\title{
Rekontruksi Model Manajemen Rurukan Dalam Upacara Adat
}

\author{
Euis Suhaenah, Ai Juju Rohaeni, Wanda Listiani \\ Insititut Seni Budaya Indonesia (ISBI) Bandung \\ Jalan Buatu no. 212 Bandung
}

\begin{abstract}
The research found the community management theory especially the rurukan management and the model of rurukan management in the ritual. Accredited Scientific journal or international reputation, memoir and the textbook for the cultural and art student are the output of this fundamental research.This research use the qualitative descriptive analysis, field observation is applied as the first step. The observation focuses on interview and event recording.The interview conducted with the performers, the prominent figures, and the artists that involved in the ritual.Depth interview technique through the main informan to get the valid data for the solid result and comprehend description. The results of this research made reference to the Sundanese social-mindset in the manner of the Tritangtu concept in ritual tradition through the three steps of the Rurukan discipline-management; Musyawarah (Conference), Ngalaksanakeun (Implementation), and Wawarian (evaluation)also called MNW.
\end{abstract}

Keywords: Community management, ritual tradition, rurukan management in Sumedang

\begin{abstract}
ABSTRAK
Penelitian ini menemukan teori manajemen komunitas khususnya manajemen rurukan dan model manajemen rurukan dalam upacara adat. Luaran penelitian Fundamental ini berupa jurnal ilmiah terakreditasi atau bereputasi internasional, laporan penelitian dan buku ajar bagi mahasiswa seni budaya. Penelitian ini menggunakan metode diskriptif analisis kualitatif, sebagai langkah awal pengumpulan data dilakukan dengan mengadakan observasi lapangan. Hal ini menitikberatkan pada pengamatan yang didukung dengan wawancara dan perekaman kejadian.Wawancara dilakukan dengan pelaku, tokoh yang terlibat langsung, dan tokoh seniman yang terlibat didalamnya.Teknik wawancara yang mendalam dengan cara memilih informan kunci guna mendapatkan validitas data yang menghasilkan deskripsi yang lebih utuh dan menyeluruh. Hasil penelitian merujuk pada pola pikir masyarakat Sunda dengan konsep Tritangtu. Dalam upacara adat ada 3 (tiga) tahapan dalam proses pengolaan manajemen rurukan; yakni musawarah, ngalaksana-keun, wawarian yang disebut MNW.
\end{abstract}

Kata kunci: manajemen komunitas, upacara adat, manajemen rurukan, Sumedang 


\section{PENDAHULUAN}

Rurukan adalah sebuah kumpulan atau organisasi adat masyarakat komunitas petani berdasarkan pemilahan wilayah di Rancakalong. Secara tradisi, perekrutan anggota rurukan satu sama lainnya masih terkait kerabat berdasarkan garis keturunan. Dalam arti luas rurukan adalah model sebuah organisasi yang bernilai dalam kehidupan lokal masyarakat Rancakalong, masyarakat yang terbangun dalam periode yang sangat panjang berevolusi bersama masyarakat dan lingkungan dalam sistem lokal. Proses tersebut dalam kehidupan masyarakat menjadi pengetahuan kolektif masyarakat lokal, sehingga nilai-nilai tersebut diyakini oleh masyarakat setempat sebagai kebenaran dan menjadi pedoman dalam melakukan sesuatu.

Berdasarkan pengamatan, menarik untuk diungkap sistem rurukan yang dianut masyarakat secara tradisi bisa menyelenggarakan sebuah perhelatan upacara ritual Ngalaksa. Pelaksanaan upacara ritual yang sakral tersebut bagi masyarakat Rancakalong telah berlangsung selama ratusan tahun. Meskipun zaman telah banyak berubah, penduduk pemilik ritual itu terus melestarikan adat warisan nenek moyang mereka. Upacara yang dikaitkan dengan persembahan untuk Dewi padi SangHyangSriPohaci, pada pelaksanaanya diiringi oleh jenis kesenian bernama Tarawangsa. Pola pikir masyarakat sawah dalam konsep rurukan tersirat dalam pemetaan jumlah rurukan. Di Rancakalong ada 5 (lima) rurukan yang menunjukkan pola pikir orang sawah dikenal dengan konsep "empat kiblat kalima pancer". Adapun pemetaaan 5 (lima) rurukan di Rancakalong sebagai berikut, yakni; rurukan Rancakalong, rurukan Cibunar, rurukan Cijere, rurukan Legok Picung, dan rurukan Pasir Biru.
Masing-masing rurukan berjumlah 30 orang yang dipimpin oleh seorang saehu atau pimpinan rurukan, dan yang lainnya berperan sebagai pelaku seni penabuh Tarawangsa, penari dan petugas khusus yang memiliki keahlian dalam bidangnya, misalnya menumbuk beras, membuat laksa, candoli, menanak nasi, memasak, ngawasuhnyai (membersihan beras), ngukus dan sebagainya.

Artikel ini mengkaji permasalahan keberadaan Rurukan dalam Upacara Ngalaksa di Kecamatan Rancakalong Kabupaten Sumedang, merupakan salah satu artefak manajemen tradisi dari organisasi masyarakat sawah-ladang. Konsep pengorganisasian rurukan membantu manajemen organisasi untuk mencapai tujuan dengan efektif dan efisien. Efektif artinya dapat menghasilkan kegiatan yang berkualitas sesuai dengan keinginan penyelenggara dan masyarakat komunitasnya. Efisien berarti menggunakan sumberdaya secara rasional dan hemat tidak ada pemborosan atau penyimpangan. Pada dasarnya manajemen adalah memanfaatkan infut untuk menghasilkan kegiatan melalui suatu proses perencanaan, pengorganisasaian, pengarahan, dan pengendalian dengan memperhatikan situasi dan kondisi lingkungan.

Selanjutnya pembahasan difokuskan pada bagaimana proses manajemen tradisi pada rurukan dalam upacara adat Ngalaksa di masyarakat petani, dari proses, perilaku hingga bentuk komunikasi tersebut eksis selama upacara adat berlangsung. Seiring dengan hal ini, pembahasan akan diarahkan juga bagaimana terinpresentasikan manajemen rurukan selaku manajerial dalam kegiatan upacara Ngalaksa di masyarakat petani Rancakalong. Persepsi dan interprestasi atas proses dan tindakan yang didasarkan atas perasaan dan 
pengalaman bersama menjadi sangat penting mengkaitkan dalam penyelenggaraan berbagai upacara adat ritual tersebut.

\section{METODE}

Metode pengumpulan data yang sesuai dengan penelitian ini dikumpulkan melalui metode kualitatif, dan pengumpulan data diawali dengan observasi langsung ke lapangan. Langkah kedua berupa pangamatan terlibat yaitu penulis melakukan pengamatan secara intensif dan keteribatan penulis secara langsung yaitu pada saat penulis terlibat sebagai juri Festival Kuda Renggong 2004 s/d 2015. Langkah ketiga, data dikumpulkan melalui wawancara mendalam terhadap sejumlah informan. Selama wawancara, penulis melakukan pencatatan, perekaman dengan taperecorder, dan pengambilan gambar dengan kamera foto.

Analisis data dilakukan, dengan cara mengidenfikasi dan menemukan hubungan-hubungan perkembangan pangatik perempuan dalam kesenian Kuda Renggong di Kabupaten Sumedang. Langkah selanjutnya, dari hasil penelitian dituangkan dalam bentuk deskriptif-analisis.

\section{HASIL DAN PEMBAHASAN}

\section{A. Rekonstruksi model manajemen} rurukan dalam upacara adat Ngalaksa

Konsep manajemen tradisi Ngalaksa Musawarah, Ngalaksanakeun, Wawarian, disingkat (MNW) yang dianut masyarakat Rancakalong mengacu pada pola pikir masyarakat Sunda Lama kaum ladang mengenal pembagian tiga atau tritunggal yang dikenal sebutan Tritangtu (Jakob Sumardjo, 2003:305). Tritangtu adalah pola tiga yang terdiri dari unsur persatuan wilayah atas dan bawah yang menghasilkan wilayah tengah. Ketiga unsur ini disimbol- kan dengan resi, ratu dan rama sebagai artefak dari masyarakat berladang, terkait juga dalam budaya padi huma. Hal ini menunjukan, bahwa ritual upacara adat Ngalaksa telah ada sejak masa berladang. Padi sebagai makanan pokok, sumber hidup dan kehidupan.dimaknai sangat sakral. Dalam bahasannya Jakob Sumardjo bahwa, padi merupakan emanasi dari benih Rama dan emanasi Nyi Pohaci. (Jakob Sumardjo, 2003: 305) Untuk itu upacara adat Ngalaksa terkait erat dengan Nyi Pohaci, sang Dewi Padi, yang dipupusti oleh manusia. Hal ini senada dengan falsafah hidup masyarakat Rancakalong kaitannya dengan Nyai Pohaci terucap dengan katakata "sanes migusti kersa Nyai, tapi mupusti kersa Nyai" (Bukan menyembah padi, tapi memelihara ciptaan Tuhan).

\section{Proses manajemen tradisi hirarki adat Ngalaksa}

Hirarki adat Manajemen Ngalaksa dengan konsep Tritangtu yang meliputi 3 (tiga) tahapan yakni; musawarah, ngalaksanakeun, wawarian. (MNW). Tahapan proses upacara adat sebagai berikut:

1. Musawarah, istilah musawarah dalam bahsa Sunda artinya, badami, berempug (Danadibrata, 2006:339). Musawarah dilakukan oleh kelima rurukan, dalam musawarah dibicarakan secara detail dari mulai persiapan yang diperlukan, kebutuhan dan kelengkapan untuk upacara adat ngalaksa. Pembentukan panitia pelaksana upacara Adat Ngalaksa yang mempunyai tanggung jawab dalam setiap tahun penyelenggaraan secara bergiliran dipegang oleh satu rurukan yang telah disepakati secara musyawarah. Rurukan merupakan wilayah yang telah terbentuk sejak lama dan ditempati orang-orang menurut 
garis keturunan, di dalam setiap rurukan terpilih tokoh adat dengan memiliki kriteria tertentu yang telah dipercayai dan disepakati, tokoh-tokoh terpilih tersebut yang akan menjadi penanggung jawab dalam keberlangsungan upacara. Upacara adat Ngalaksa ini bersifat kolektif, sebuah upacara yang melibatkan berbagai kelompok masyarakat dan menyeluruh di beberapa daerah yang melibatkan setiap anggota masyarakat, keterlibatan tersebut dapat memberi sumbangan berupa; beras, uang, padi, makanan ringan/hahampangan (kue panganan tradisi misalnya, tengteng, kolontong, opak, rangginang, ranggining, dan sebagainya), ikan, ayam, kayu bakar dan lain sebagainya. Dalam upacara adat ngalaksa terdapat upacaraupacara ritual kecil yang terjalin menjadi satu kesatuan. Upacara ini bertujuan membangkitkan kembali dan memelihara kesuburan tanah.

2. Ngalaksanakeun, ngalaksa-keuna adalah sebuah kegiatan membuat makanan yang disebut laksa, masyarakat Rancakalong mengatakan ngalaksa sebagai kontraksi dari kata ngalaksanakeun (melaksanakan). Dalam pengertian mereka, ngalaksa berarti melaksanakan sesuatu sesuai dengan petunjuk atau perintah ajaran Karuhun. Dibalik itu semua pelaksana kegiatan Ngalaksa dilakukan oleh rurukan, tahap demi tahap rurukan melakukan prosesi upacara adat Ngalaksa dengan penuh tanggung-jawab dan dedikasi tinggi, keberhasilan upacara Ngalaksa merupakan akumulasi rurukan sebagai pelaksana kegiatan, melakukan dengan senanghati tanpa beban.

3. Wawarian, merupakan tahapan terakhir rangkaian upacara adat Ngalaksa. Istilah wawarian berasal dari peribahasa Jawa mamarian, dalam bahasa Sunda kosa katanya berubah menjadi wawarian, artinya makanan sisa keduri atau hajatan (R.H. Hasan Mustopa, 1991: 244). Dalam pengertian di masyarakat Rancakalong Wawarian merupakan upacara penutup bertujuan meminta maaf atas kekurangan dalam penyelenggaraan ngalaksa dan suatu wujud rasa syukur terhadap limpahan atas karuniaNya dalam bentuk hasil pertanian atau panen. Selain itu juga, merupakan ajang evaluasi bagi penyelenggara yang dilaksanakan pada tahun

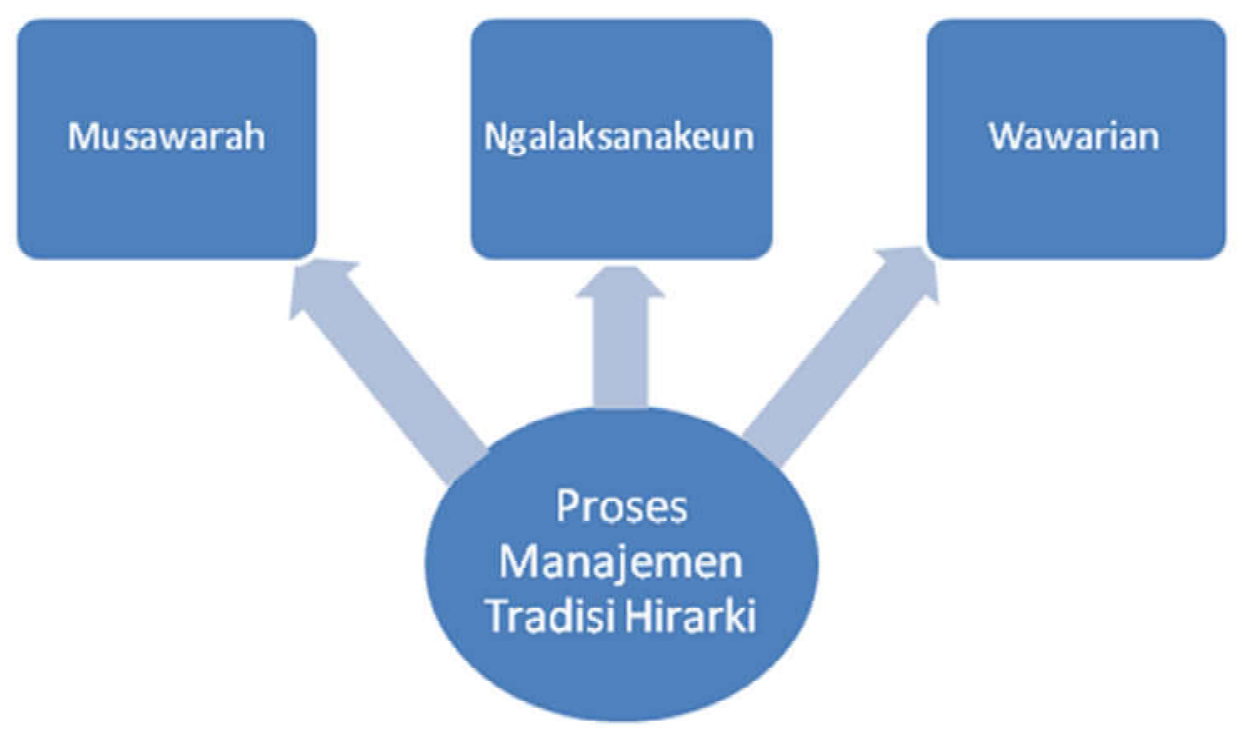


berikutnya, misalnya hal-hal yang menyangkut keberhasilan dan kekurangan atas kendala yang dihadapi dalam upacara adat Ngalaksa, ketika wawarian dipaparkan dengan transparansi dan penuh kekeluarga.

Hirarki adat manajemen Ngalaksa dengan konsep Tritangtu Musawarah. Ngalaksanakeun dan Wawarian (MNW), yakni tiga tahapan tatanan manajemen tradisi Ngalaksa. Hal ini jelas menunjukkan pola pikir masyarakat Sunda dulu yang dikenal dengan Tritangtu.Konsep Tritangtu ini merupakan gambaran hidup masyarakat ladang yang lahir dari pikiran dualisme antagonistik. Hal ini senada dengan pendapat Yacob Sumardjo; dalam naskah naskah Sunda Lama disebut adanya azas tritunggal kesetaraan dalam hidup masyarakat, yaitu tritangtu yang terdiri dari Resi (pemimpin agama), Rama (pemimpin rakyat pedesaan), Perebu (raja penguasa seluruh wilayah) (Jakob Sumardjo, 2003: 249). Azas keserataan tritangtu di masyarakat Rancakalong juga masih hidup dalam bentuk upacara adat ritual Ngalaksa, karena upacara adat ritual Ngalaksa merupakan suatu kesatuan rurukan untuk mempertahankan adat dengan kukuh, maka tidak terdapat perbedaan antara adat, Islam, dan pemerintahan. Masyarakat Rancakalong bersikukuh dan mempertahankan azas tiga kemananggulan dalam kesetarataan yang diyakini merupakan pola ketringgunggalan ini mendasari semua produk budaya yang berstruktur ketritunggalan seperti halnya rurukan dalam upacara adat Ngalaksa menjalani aktivitasnya dengan konsep 3 (tiga) tahapan; musawarah, ngalaksanakeun, wawarian (MNW), hal ini jelas masih menunjukkan ciri pola masyarakat Sunda.

Jakob Sumardjo menjelaskan, bahwa petani ladang hidup dari menanam, memelihara, dan mengembangkan padi, serta tanaman-tanaman sampingan lainnya. Obsesinya adalah menghidupkan tanaman padi. Mereka harus merawat dan memelihara tanaman pokoknya agar terus hidup. Pikiran mereka jauh dari "merampas" yang hidup. Bukan mematikan. Hidup adalah memelihara kehidupan, dalam hal ini mengawinkan pasangan oposisi yang saling bertentangan, tetapi saling melengkapi. Dari perkawinan itulah kehidupan yang baru muncul. Begitu terjadi pada manusia,

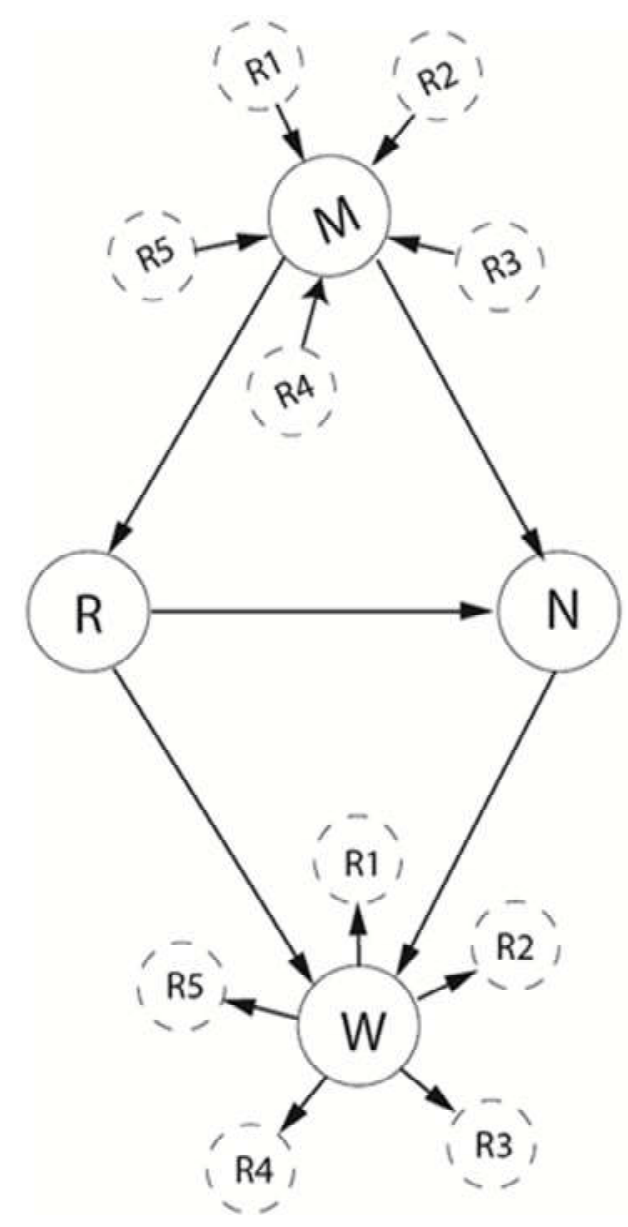

MODEL MANAJEMEN KOMUNITAS MNW

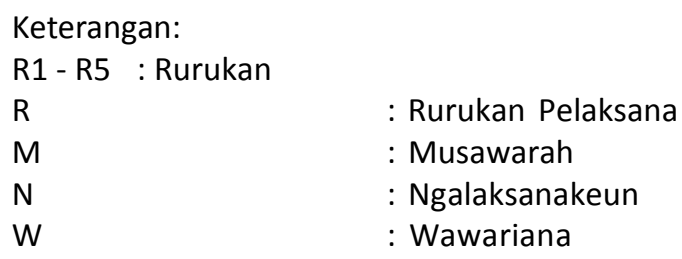

Gambar 1.

Model Manajemen Komunitas MNW 
hewan, tumbuh dan alam.Tanaman padi dapat terus hidup kalau ada perkawinan antara langit dan bumi. Langit mencurahkan hujannya kepada tanah yang kering. Langit dan Bumi juga adalah simbol lelaki dan perempuan (Jakob Sumardjo, 2006:72). Ngalaksa dengan Tarawangsa adalah salah satu bentuk menghidupkan, mengharmonikan dalam menemukan wilayah transeden untuk mendapatkan berkah yang diharapkan manusia.

\section{B. Aplikasi Model MNW dalam Pem- belajaran Matakuliah Manajemen Produksi Seni}

Penerapan dari manajemen rurukan MNW (Musawarah, Ngalaksanakeun dan Wawararian) ini telah diaplikasikan pada materi mata kuliah Manajemen Produksi Seni Prodi Tari semester V dengan jumlah siswa 53 ( lima puluh tiga) orang dibagi dalam 3 (tiga) kelas.

Diakhir perkuliahan sebagai UAS MK Manajemen Produksi Tahun Ajaran 2014/ 2015, mahasiswa dituntut untuk mengaplikasikan teori manajemen rurukan MNW, yang bermanfaat pada keahlian dan keterampilan yang dituangkan dalam sebuah pertunjukan yang bertema Memperkenalkan Seni Tradisi Kepada Masyarakat. Dalam kegiatan UAS tersebut mengusung tema diberi nama Keep Your Art (jaga kesenian), yang bermakna, Hidup Tanpa Seni Terasa Hambar. Seni adalah kebutuhan manusia yang harus dijaga. Sebagai laporan akhir dari pelaksanaan metode pengajaran dengan fungsi MNW, mahasiswa dituntut untuk menjelaskan dari mulai tahapan Musawarah sampai dengan tahapan Wawarian yang dilaksanakan di luar lingkungan kampus ISBI yaitu di Kampung Budaya Karawang, mahasiswa kerjasama dengan Pemerintah Kabupaten Karawang.
MOU telah disepakati dari ISBI selaku Event Organizer (EO) yang merancang kegiatan dan sumber daya manusia (SDM), sarana dan biaya kepanitian dan Pemda Karawang menyediakan sarana, tempat, biaya kegiatan dan mengkoordinir para seniman Karawang yang terlibat dalam kegiatan.

Pembagian kerja dalam Mata Kuliah Manajemen Produksi dipilah mahasiswa sebagai panitia penyelenggara dan pengisi acara. Pengisi acara telah dirancang selain dari para mahasiswa ISBI, juga melibatkan para seniman dari Kabupaten Karawang. Dalam rencana kegiatan ini dirinci kegiatan yang akan dilakukan, waktu, tempat, jadual, biaya yang diperlukan, dan penanggung jawab kegiatan. Selanjutnya proses pembagian kerja dan pembentuk team panitia pelaksana.

\section{Proses Manajemen MNW}

1. Musawarah; dalam tahapan musawarah mahasiswa dan team pangajar mengadakan pertemuan untuk merancang kegiatan, diawali dibentuk organisasi panitia penyelenggara (pengorganisasian) terdiri dari ketua, sekertaris, ben-dahara setelah terbentuk panitia inti (ketua, sekertaris, bendahara), para penatia inti ini yang bertugas menyu-sun panitia yang lengkap sesuai dengan kebutuhan kegiatan. Dibentuknya peorganisasian merupakan kegiatan yang dilakukan untuk menjamin agar kemampuan orang-orang yang ada didalam organisasi dapat dimanfaat secara optimal. Hal ini diwujudkan dalam susunan panitia yang dilengkapi dengan uraian pekerja. Berikut di bawah ini susunan panitia pelaksana yang berisi tugas dan wewenang masing-masing anggota. Penanggung Jawab: Ketua Prodi Tari

Penasehat : Team Teaching 
MK Manajemen Produksi

Ketua : Fitria

Sekretaris : Neng Otih

Bendahara : Desi Purnamasari

Penata Panggung : Indiran Azalia

Pengatur Acara : Elin Ratna Yulia

Humas

: Rima Dini

Komsumsi

: Meielisa, Gita

Seika, Wulandari

Dokumentasi : Mariah Al-Qibtyah

Dekorasi

: Siti Hani Rohaeni

Pembantu Umum : Deri Al-Badri,

Ayi Rahmat

Transfortasi/

akomodasi : Mega Fajar A

Penerima tamu : Latifah Mulyati

Deskripsi kerja Panitia Keep Your Art

1. Penanggung Jawab adalah Ketua Prodi Tari ( Dindin Rasidin S.Sen ,Mhum), penangung jawab dari keseluruhan kegiatan pelaksannaan kegiatan UAS MK Manajemen Produksi.

2. Penasehat adalah Team Teaching MK Manajemen Produksi ( Euis Suhaenah. SST,MSn, Ida Farida S.Sen,.MSn, Ocoh Suherti S.Sen,MSn, Jaja MD S.Sen, $\mathrm{MM}$ ) sebagai konsultan kegiatan, memberi pandangan-pandangan dan petunjuk selama kegiatan serta memberi penilaian diakhir kegiatan.

3. Ketua pelaksana adalah (Fitria); memimpin seluruh rangkaian kegiatan. Laporan dan bertanggung jawab kepada Team Teaching MK Manajem Produksi.

4. Sekertaris adalah (Neng Otih); koordinator sekerariat menyangkut suratmenyurat seluruh kegiatan, laporan dan bertanggung jawab kepada ketua pelaksana

5. Bendahara adalah (Desi Purnamasari); mencatat pemasukan dan pengeluaran dana untuk kepentingan kegiatan, laporan dan bertanggung jawab kepada ketua pelaksana.
6. Stage Manager/ pimpinan panggung pertunjukan adalah (Indira Azalia); memimpin, mengatur penyajian materi pertunjukan; laporan dan bertanggungjawab kepada ketua pelaksana.

7. Pengatur acara adalah (Elin Ratna Yulia); menyusun urutan acara kegiatan panitia dan acara pertunjukan, laporan dan bertanggung jawab kepada ketua pelaksana.

8. Humas adalah (Rima Dini), koordinasi ke kelompok masyarakat yang mendukung/sponsor khususnya dalam bidang pendanaan. Laporan dan bertanggung jawab kepada ketua pelaksana.

9. Komsumsi adalah (Meielisa, Gita Seika, Wulandari), mengatur makanan untuk panitia dan pengisi acara kegiatan. Laporan dan bertanggungjawab kepada ketua pelaksana.

10. Dekomentasi adalah (Mariah AlQibtyah), mengatur kegiatan pendokomentasian berupa foto dan idio kegiatan. lLaporan dan bertanggung jawab kepada ketua pelaksana.

11. Dekorasi adalah (Hani Siti Rohaeni), mengatur dekorasi panggung pertunjukan. Laporan dan bertanggung jawab kepada ketua pelaksana.

12. Pembantu Umum adalah (Deri Al-Badri, Ayi Rahmat), membantu semua anggota panitia untuk kepentingan kegiatan. Laporan dan bertanggungjawab kepada ketua panitia.

13. Transformasi/akomodasi adalah (Mega Fajar Alamsyah), mengatur dan menyediakan sarana transformasi dan penginapan bagi seluruh panitia dan pengisi acara kegiatan.oran dan bertanggungjawab kepada ketua pelaksana.

14. Penerima tamu adalah ( Latifah Mulyati), mencatat dan mengatur tamu undangan yang hadir dalam kegiatan. 
Laporan dan bertanggungjawab kepada ketua pelaksana.

Tahap selanjutnya mengurut kegiatan yakni merancang bentuk pertunjukan sesuai dengan tema yang diusung oleh team panitia ISBI dan panitia dari Pemda Karawang. Seniman tradisi dari Karawang yang mengisi acara terdiri dari; Kesenian Odong-odong/Sisingaan yaitu seni helaran yang ada di Karawang, Sanggar Surya Medal , Karinding, group Kuntum Mekar . sedangkan dari mahasiswa ISBI Bandung adalah rampak kendang dari prodi Karawitan, Rookii Cookie Percussion, Tari Pembukaan/Penyambutan tamu dari prodi tari dan karawitan, tari Cikeruhan dan tari bersama.

Kegiatan ini bersifat kolektif, yakni kegiatan yang melibatkan berbagai kelompok/organisasi masyarakat dari wilayah Kabupaten Karawang. Setiap organiasi masyarakat boleh memberi sumbangan berupa apapun uang untuk menunjang kegiatan tersebut.

2. Ngalaksanakeun; dalam proses melaksanakan pekerjaan sesuai dengan petunjuk rancangan yang telah disepakai bersama antara panitia penyelenggarakan dengan pihak pemerintah Daerah Kabupaten Karawang yang diwakil ioleh Dinas Pariwisata Kabupaten Karawang. Implementasinya berpedoman pada perencanaan dan yang dilengkapi dengan pengorganisasian. Indikasi keberhasilan pelaksanaan kegiatan tersebut ditandai dengannya pelaksanaan lancar sesuai dengan harapan.

Prosesnya diawali oleh adanya instruksi dan komunikasi ketua pelaksana, serta memotivasi orang agar menjalankan tugasnya dengan baik. Hal ini akan lebih mudah dijalani, jika ketua pelaksana memahami dengan baik orang yang dipimpinnya, dan kemudian mrnggunakan pendekatan yang tepat untuk menggerakannya.

3. Wawarian, merupakan tahapan akhir merupakan ajang evaluasi kegiatan yang telah diselenggarakan, dengan tujuan untuk mengetahui sampai sejauh mana kegiatan tersebut kekurangan dari apa yang telah direncanakan. Tahapan Wawarian ini sebagai evaluasi yang dilakukan oleh Pemda Karawang selaku patner kegiatan dan team Teaching Mata Kuliah Manajemen Produksi selaku team penguji kegiatan. Begitu pula dalam acara wawarian ini disampaikan laporan secara tertulis sebagai wujud pertangungjawaban penggunaan dana selama kegiatan berlangsung.

Proses tahapan penerapan fungsi manajemen rurukan yang disebut MNW dapat dikatakan berhasil, walaupun metode ini merupakan manajemen tradisi yang telah bertahun-tahun dilakukan oleh para seniman dan masyarakat komunitas petani Kecamatan Rancakalong Kabupaten Sumedang. Aplikasi teori MNW kepada kegiatan Keep Your Arts telah dilaksanakan langsung terjun kelapangan. Indikatornya semua yang dirancang sesuai dengan pelaksanaan ,dan harapan. Pertunjukan dapat sambutan dari masyakat dan panitia Pemda Karawang program Dinas Pariwisata Kabupaten Karawang dapat dilaksanakan dengan sukses atas bantuan kegiatan UAS Mata Kuliah Manajemen Produksi.

Manajemen produksi seni sebelumnya selalu menggunakan teori yang dikemukakan G.R Terry yaitu POAC, berdasarkan praktik di lapangan yang telah dilaksanakan teori manajemen Rurukan MNW telah memenuhi kebutuhan untuk mengelola sebuah pertunjukan seni.

\section{SIMPULAN}

Rurukan merupakan organisasi tradisi lama sebagai pengelola dalam upacara adat 
Ngalaksa dengan pengelolaan diwariskan secara turun-temurun. Dengan kata lain, arti luas rurukan adalah model sebuah organisasi tradisi yang bernilai dalam kehidupan lokal masyarakat Rancakalong, masyarakat yang terbangun dalam periode yang sangat panjang berevolusi bersama masyarakat dan lingkungan dalam sistem lokal, proses tersebut dalam kehidupan masyarakat dan menjadi pengetahuan kolektif masyarakat lokal. Sehingga nilai-nilai tersebut diyakini oleh masyarakat setempat sebagai kebenaran dan menjadi pedoman dalam melakukan sesuatu.

Upacara adat ngalaksa merupakan salah satu bentuk upacara persembahan untuk NyiPohaci yang dilakukan dalam rangka memohon kesuburan lahan pertanian dalam sistem mata pencaharian masyarakat Rancakalong. Meskipun ritual ini dilaksanakan dalam jangka waktu lama.Hal ini menunjukkan sistem kepercayaan masyarakat Rancakalong pada hakekatnya terkait dengan sumber utama kehidupan mereka, yaitu pertanian.Upacara adat Ngalaksa dalam praktiknya berupa kegiatan pembuatan makanan lontong yang dijadikan sebagai ritual besar, sentral dari semua ritual yang dilakukan oleh masyarakat Rancakalong.

Pengelolaan upacara adat Ngalaksa merupakan manajemen tradisi lama dengan konsep 3 (tiga) tahapan yang merujuk pada pola pikir Sunda Tritangtu yakni; Musawarah, Ngalaksanakeun, Wawarian yang disingkat dengan istilah MNW. Dari penelitian yang telah dilaksanakan melalui data dan fakta serta nara sumber yang ditemui, penyelenggaraan Upacara adat yang telah berlangsung sampai sekarang, konsep manajemen tradisi masyarakat lokal yang dianut dari setiap rurukan bisa mempertahankan salah satu kebudayaaan tradisi, fungsi MNW juga mencerminkan gamabran dari pola kehidupan bermasyarakat yang dianut dari setiap rurukan di masyarakat Rancakalong. Hal ini menunjukkan masyarakat Rancakalong dengan konsep kearifan lokal yang dianut dan dimilikinya secara turun-temurun yakni sebagai pengelola kegiatan tradisi yang menjadi pedoman hidupnya yang dipraktikan dalam kehidupan sehariharinya

\section{Daftar Pustaka}

Achsan Permas,dkk.

2003 Manajemen Organisasi Seni Pertunjuka. Jakarta: PPM

Casserer, Ernst.

1987 ManusiadanKebudayaan. Jakarta: Gramedia

Dhavamony Mariasusai

1995 Fenomenologi Agama. Yogyakarta : Kanisius

Euis, Suhaenah,.

2000 Profil Desa Wisata Rancakalong Sebagai Salah Satu Tujuan Daerah Wisatawan di Kabupaten Sumedang. Bandung : Laporan Penelitian Sekolah Tinggi Seni Indonesia (STSI) Bandung.

2012 Rurukan dalam upacara adat Ngalaksa di Rancakalong. Laporan Penelitian Sekolah Tinggi Seni Indonesia (STSI) Bandung.

Pananrangi Hamid

1989 Wawasan Metodologi Penelitian . Program Pascasarjana Hasanudin Ujung Pandan

Jacob, Sumardjo.

2000 Filasafat Seni. Bandung : ITB

2003 Simbol-simbol Artefak Budaya Sunda. Tafsir-Tafsir : Pantun Sunda. Bandung: Kelir

2006. Estetika Paradoks.Bandung: Sunan Ambu Press 
Nurlaela, Ningsih.

2006 Struktur dan Fungsi Dalam Upacara Adat Ngalaksa di Rancakalong. Tesis Pascasarjana Pengkajian Seni Pertunjukan Insititut Seni Indonesia (ISI) Yogyakarta

Sal, Murgiyanto,.

1983 Manajemen Pertunjukan. Jakarta. Depdikbud
Soedarsono,

1999. Metodologi Penelitian Seni Pertunjukan dan Seni Rupa.Bandung. Masyarakat Seni Perunjukan Indonesia (MSPI) 